Original Research Article

\title{
Drug utilization study of antibiotics in infectious diseases in a tertiary care hospital
}

\author{
Kirti Rangdal $^{1}$, Anand Kanaki ${ }^{1}$, Ketan Patil ${ }^{2 *}$
}

${ }^{1}$ Department of Pharmacology, M. R. Medical College, Kalaburagi, Karnataka, India ${ }^{2}$ Department of Pharmacology, All India Institute of Medical Sciences, Jodhpur, Rajasthan, India

Received: 17 January 2019

Accepted: 16 February 2019

\section{*Correspondence to:}

Dr. Ketan Patil,

Email: patilkak@gmail.com

Copyright: (c) the author(s), publisher and licensee Medip Academy. This is an openaccess article distributed under the terms of the Creative Commons Attribution NonCommercial License, which permits unrestricted noncommercial use, distribution, and reproduction in any medium, provided the original work is properly cited.

\begin{abstract}
Background: Infectious diseases represent a major cause of mortality and morbidity in India. Irrational use of antibiotics can cause increase adverse drug reaction, leading to antibiotic resistance and increase in the treatment cost. Hence pattern of use of antibiotics need to be studied, therefore the aim of our study is to observe the antibiotics prescription pattern and drug utilization in department of medicine indoor patients at our tertiary care hospital.

Methods: This was a prospective observational study carried out among indoor patients admitted in medicine ward and was conducted between January 2018 to March 2018 in Basaveshwara Teaching and General Hospital attached to M.R. Medical College, Kalaburagi. The data that was obtained was analysed and presented as percentages using descriptive statistics.

Results: 100 patients were enrolled. The main reasons for admission were for diagnosis of respiratory tract infection $(36 \%)$, GIT disorders $(24 \%)$, Zoonotic disease $(10 \%)$, Urinary tract infection $(19 \%)$ and viral fever $(11 \%)$. Most common antibiotic prescribed was ceftriaxone (40\%), followed by piperacillin $(26 \%)$. Average number of antibiotics per prescription was 1.7.

Conclusions: For a wide spectrum of clinical diagnoses variety of drugs were utilized from various drug classes. Results showed that Cephalosporin was extensively used. As antibiotics are most commonly prescribed drugs and report of misuse is not uncommon so proper strategy like educational intervention and antibiotic policy are necessary to control this.
\end{abstract}

Keywords: Antibiotic, Drug utilization, Prescription pattern, Rational use

\section{INTRODUCTION}

Drug utilization study is a component of medical audit that does monitoring and evaluation of the drug prescribing patterns and suggests necessary modifications in prescribing practices to achieve rational therapeutic practice as well as cost effective health care. ${ }^{1}$

The rational use of drugs require the patient to receive medicines appropriate to their needs in doses that meet their individual requirement for adequate period of time and at lowest cost. ${ }^{2}$ Medically inappropriate, ineffective, non-economic use of pharmaceutical product is commonly observed in health care system throughout the world and especially so in developing countries. ${ }^{3}$ Antibiotics today are commonly prescribed drugs in a hospital set up. Successful use of antibiotics has brought a revolutionary change in management of infectious diseases but it also resulted over use and misuse of antibiotics. ${ }^{4}$ Surveys have shown that $22-65 \%$ of antibiotic prescriptions are either inappropriate or incorrect. ${ }^{5,6}$ Several authors have reported concern about the continuous indiscriminate and excessive use of antibiotics that promote the emergence of antibioticresistant organisms. Monitoring of antibiotics use and knowledge of prescription habits are some of the strategies recommended to contain resistance to antibiotics in hospitalized patients. ${ }^{7,8}$ Drug utilization studies aim to 
evaluate factors related to the prescribing, dispensing, administering and taking of medication, and its associated events either beneficial or adverse.

These studies are useful to provide denominators to calculate rates of reported adverse drug reactions, to monitor the utilization of drugs from therapeutic categories where particular problems can be anticipated. ${ }^{9}$ Drug utilization research may generate hypothesis that sets the agenda for rational prescribing and to prepare essential drug list to minimize irrational use of drugs. Rational use of drugs plays a vital role in cost minimization and optimal utilization of available funds as drug cost is a major concern for both health care providers and the beneficiaries in the developing countries. ${ }^{10}$ Hence, through this study an attempt is being made to show the current status of prescribing antibiotics in our tertiary care hospital

Aims and objectives was to assess the prescribing patterns of different classes of antibiotic drugs and to assess rationality of drug use.

\section{METHODS}

A prospective, cross sectional, observational study was carried out among in-patients admitted in medicine ward in Basaveshwara Teaching and General Hospital attached to M.R. Medical College, Kalaburagi. The study period was for three months from January 2018 to March 2018. Sample size was calculated to be 100 by estimation technique. The study was conducted after obtaining approval from institutional ethics committee.

\section{Inclusion criteria}

- Patient of either gender aged 20-50 yrs,

- Diagnosed with infective conditions and on antimicrobial drugs,

- Admitted in medicine general ward.

\section{Exclusion criteria}

- $\quad$ Patient suffering from HIV, TB and other chronic infective condition.

- Pregnant and lactating women.

Patient fulfilling above criteria were included in the study after taking written informed consent. Demographic details of patients, diagnosis of disease and data about intake of antibiotic agents and other drugs were collected from the in-patient case sheet of General medicine ward. Rationality of prescription was assessed by using WHO core prescribing indicators like:

- Average number of drugs per prescription,

- Percentage of drugs prescribed by generic name,

- Percentage of encounters with an injection prescribed.

- Percentage of drugs prescribed from essential drugs list or formulary.

\section{Statistical analysis}

The data collected were analyzed statistically using descriptive statistics. The result is expressed in form of mean. Wherever necessary the results will be depicted in the form of percentage and graphs. Microsoft Excel and Statistical Package for Social Sciences (SPSS) were used for statistical analysis.

\section{RESULTS}

A total of 100 patients were included in the study. Out of this $44 \%$ were males and $56 \%$ were females, mean age of patients was 36.29 years (Figure 1). $68 \%$ of patient were from urban locality and $32 \%$ were from rural area. Majority of patients were of age group 20-30yrs (Figure 2). The main reasons for admission were for diagnosis of respiratory tract infection $(36 \%)$, gastrointestinal tract infection $(24 \%)$, zoonotic disease $(10 \%)$, urinary tract infection (19\%), viral fever $(11 \%)$ data depicted in Figure 3.

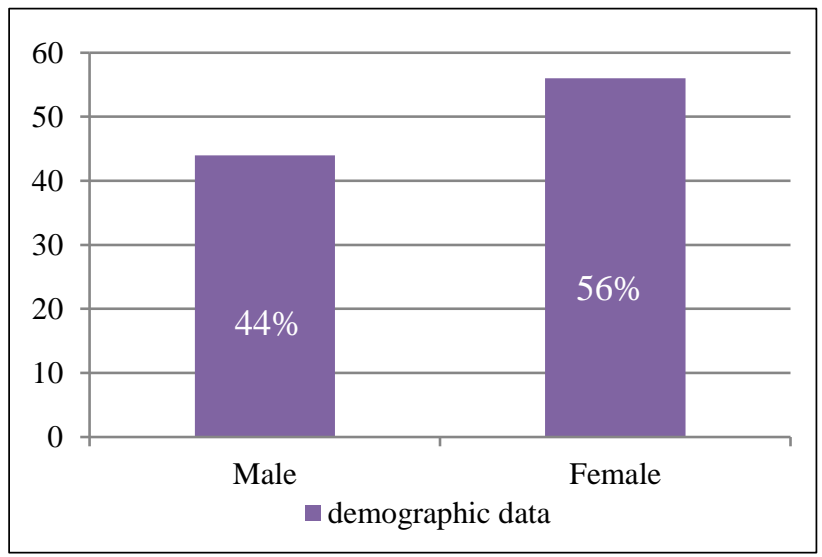

Figure 1: Demographic data.

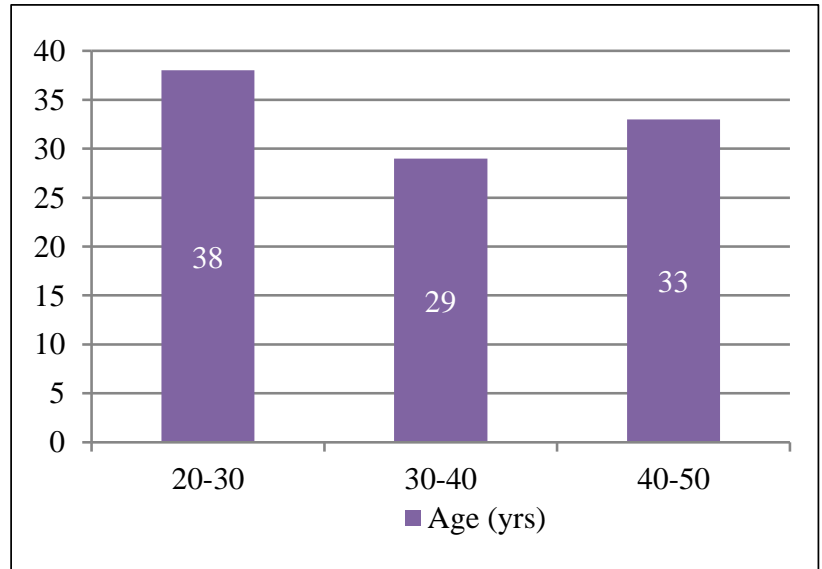

Figure 2: Age (yrs).

The major class of drugs prescribed was antibiotics (100\%) (Table 1). Most common antibiotic prescribed was ceftriaxone $(40 \%)$ followed by piperacillin (26\%), 
cefoperazone $(5 \%)$, cefuroxime $(3 \%)$, chloroquine $(2 \%)$ (Table 2).

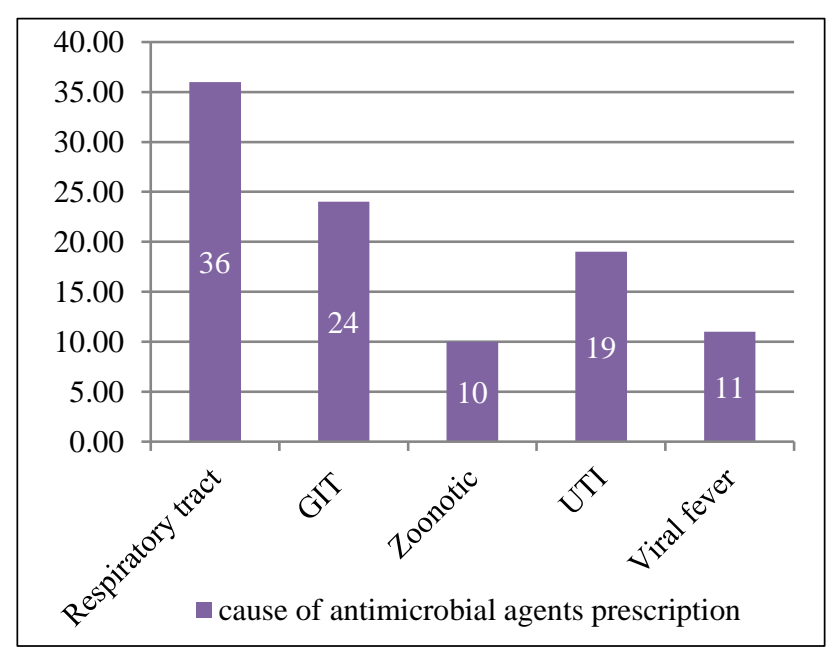

Figure 3: Cause of antimicrobial agents' prescription.

Table 1: Class of drugs prescribed.

\begin{tabular}{|ll|}
\hline Drugs & Percentage \\
\hline Antimicrobials & $100 \%$ \\
\hline NSAIDs & $95 \%$ \\
\hline Bronchodilator & $48 \%$ \\
\hline Rehydration fluids & $89 \%$ \\
\hline Antispasmodics & $10 \%$ \\
\hline Probiotics & $15 \%$ \\
\hline
\end{tabular}

Table 2: Percentage of antimicrobials prescribed.

\begin{tabular}{|ll|}
\hline Antimicrobials & Percentage \\
\hline Ceftriaxone & $40 \%$ \\
\hline Piperacillin & $37 \%$ \\
\hline Cefoperazone & $12 \%$ \\
\hline Cefuroxime & $8 \%$ \\
\hline Chloroquine & $3 \%$ \\
\hline
\end{tabular}

Table 3: Combination of antimicrobials prescribed.

\begin{tabular}{|ll|}
\hline Antimicrobials & Percentage \\
\hline Pipericillin + Tazobactum & 35 \\
\hline Cefeperazone + Sulbactum & 12 \\
\hline Cefuroxamine + Clavulunate & 6 \\
\hline
\end{tabular}

Many drugs were prescribed in various combinations in most of the patients like cefoperazone with tazobactum, piperacillin with tazobactum, multivitamins and antihistamines with bronchodilators and cough suppressants with antihistamines. Among the antimicrobials most common prescribed combination is piperacillin with tazobactum in $35 \%$ cases (Table 3 ). Average duration of stay in the study was 4.9 days. The WHO core prescribing indicators were analysed. Average number of drugs per prescription in our study was 4.2. Percentage of drugs prescribed by generic name was only $14 \%$. In $87 \%$ of cases injectable drugs were prescribed.
Percentage of drugs prescribed from essential drugs list or formulary was $78 \%$.

\section{DISCUSSION}

Drugs play an important role in improving human health and promoting well-being. Irrational use of antibiotics is a significant contributor for development of antibiotic resistance. As antibiotic resistance has posed a significant threat to management of infectious diseases and incidence of antibiotic resistance is increasing day by day, urgent steps are needed to promote rational use of antibiotics. ${ }^{11}$ Antibiotics utilization study can help in fostering the habits of rational use of antibiotics which means at right dose, for right duration and at right cost. Antibiotics are important category of drugs and its improper use can result in antibiotic resistance. ${ }^{12}$ In our study $44 \%$ were males and $56 \%$ were females which corroborates with findings of Meher BR et al. ${ }^{13}$ Most common antimicrobial administered in our study was Cephalosporin and $\beta$ lactamase was the second most prescribed drug. Similar result was shown by another study done by Chaudary PK et al and Ramesh A et al. ${ }^{14,15}$

In our study cephalosporin $(48 \%)$ were prescribed as first line antibiotics. Another study by Drupad HS et al showed cephalosporins $(43.1 \%)$ as the first line antibiotics, the reason for prescribing cephalosporins is that it is costeffective as well as covers majority of bacteria's. ${ }^{16} \mathrm{~A}$ similar result was shown in study done by Badar et al. ${ }^{17}$ Most common antibiotic among cephalosporins prescribed in our study was ceftriaxone which correlated well with study done by Meher BR et al. ${ }^{13}$ But another study done by Shankar et al showed that ampicillin was most commonly prescribed $\beta$ lactam antibiotic. ${ }^{18}$

Among second line antimicrobials, penicillin derivative pipercillin+tazobactum combination was prescribed. Reason for choosing the above drug is that it's has a variety of antimicrobial activity and is active against the organisms which have shown resistance to cephalosporin's. ${ }^{15}$ Antibiotics were mostly prescribed by their brand names and only $14 \%$ antibiotics were prescribed by their generic names which corroborates with finding of Meher BR et al. ${ }^{13}$ The average number of drugs per prescription in the present study was higher than the ideal WHO standard which is less than two (1.6-1.8). ${ }^{19}$ We also found that more than half of patients were given two or three medicines. In upper respiratory tract infection combination of bronchodilators, cough suppressants and antihistamines were most commonly used. Multivitamins were over prescribed. Thus, it is evident that the polypharmacy and over prescribing are common in our study. Antimicrobials were also prescribed in the viral diseases like common cold and viral flu which is not a rational prescription.

\section{CONCLUSION}

In conclusion, different type's clinical diagnoses were observed, and a variety of drugs were utilized from various 
drug classes. Overall, scope for improving rational use of antibiotic agents exists. Our study concluded that most common disease for which antibiotics prescribed was respiratory tract infection. Most common antibiotic used was ceftriaxone; more than one antibiotic was prescribed. There was overprescribing of drugs to the in-patients that need a special attention of all doctors and clinical pharmacists to work together to establish a rational protocol for clinical use of drugs. This study revealed that polypharmacy and prescription by brand name were common. Use of generic name in the prescriptions needs to be promoted. A strict protocol for prescribers is required to promote rational use of antibiotics which would not only prevent antibiotic resistance but also reduce the treatment expenditure.

\section{ACKNOWLEDGEMENTS}

Authors would like to thank Department of Medicine for their assistance during study. Special memorable thanks to staffs, colleagues of Pharmacology Department for their guidance and providing the necessary facilities for study.

Funding: No funding sources

Conflict of interest: None declared

Ethical approval: The study was approved by the Institutional Ethics Committee

\section{REFERENCES}

1. Srishyla MV, Mahesh K, Nagarani MA, Andrade C, Venkataraman BV. Prescription audit in an Indian hospital setting using the DDD (Defined Daily Dose) concept. Indian J Pharmacol. 1994;26:23-8.

2. Ansari KU, Singh S, Pandey RC. Evaluation of prescribing pattern of doctors for rational drug therapy. Indian J Pharmacol. 1998;30(1):43-6.

3. Melrose D. Double deprivation public and private drug distribution from the perspective of the third world's poor. World Dev. 1983;11(3):181-6.

4. Lesar TS, Briceland LL. Survey of antibiotic control policies in university affiliated teaching institutions. Ann Pharmacother. 1996;30:31-4.

5. Sjoqvist F, Birkett D. Drug utilization. WHO publications. 1975;5:39-50.

6. Niederman MS. Appropriate use of antimicrobial agents: Challenges and strategies for improvement. Crit Care Med. 2003;31:608.

7. Brink A, Feldman C, Richards GA, Moolman G, Senekal M. Emergence of extensive drug resistance among gram negative bacilli in South Africa looms nearer. S Afr Med J. 2008;98:586-92.

8. Safadar N, Maki DG. The commonality of risk factors for nosocomial colonization and infection with antimicrobial resistance Staphylococcus aureus, Enterococcus, Gram negative bacilli, Clostridium difficle and Candida. Ann Intern Med. 2002;136:83444.

9. Gama H. Drug utilization studies. Arquivos de Med. 2008;22(2/3):69-74.

10. John LJ, Devi P, John J, Arifulla M, Guido S. Utilization patterns of central nervous system drugs: A cross sectional study among the critically ill patients. J Neurosci Rural Pract. 2011;2:119-23.

11. JEJr McGowan. Economic Impact of Antimicrobial Resistance. Emerg Infect Dis. 2001;7:286-92.

12. Peripi SB, Thadepalli VG, Khagga M. profile of antibiotic consumption, sensitivity and resistance in an urban area of Andhra Pradesh, India. Singapore Med J. 2012;53(4):268-72.

13. Meher BR, Mukharjee D. Udayshankar. A study on antibiotic utilization pattern in a general medicine ward of a tertiary care teaching hospital. J Chem Pharm Res. 2014;6:1847-9.

14. Chaudhary KP, Maurya AK. Drug utilization pattern in medicine department in a tertiary care teaching hospital in Uttar Pradesh. Indo Am J Pharm Res. 2015;5(03):1164-69.

15. Remesh A, Salim S, Gayathri AM. Antibiotics prescribing pattern in the in-patient. Departments of a tertiary care hospital. Arch Pharma Pract. 2013;4:716.

16. Drupad HS, Nagabushan H, Prakash GM. Prospective and observational study of antimicrobial drug utilization in medical intensive care unit in a tertiary care teaching hospital. Int $\mathbf{J}$ Pharmacol Res. 2016;6(1):13-7.

17. Badar VA, Navale SB. Study of prescribing pattern of antimicrobial agents in medicine intensive care unit of a teaching hospital in Central India. JAPI. 2012;60:203 .

18. Shankar RP, Partha P, Shenoy NK, Easow JM, Brahmadathan KN. Prescribing patterns of antibiotics and sensitivity patterns of common microorganisms in the Internal Medicine ward of a teaching hospital in Western Nepal: a prospective study Annals Clin Microbiol Antimicrob. 2003;2:7.

19. WHO. How to investigate drug use in health facilities: selected drug indicators, action program on essential drugs (DAP), Geneva, 1993:12-25. Available at: http://apps.who.int/medicinedocs/en/d/Js2289e/.

Cite this article as: Rangdal K, Kanaki A, Patil K. Drug utilization study of antibiotics in infectious diseases in a tertiary care hospital. Int J Basic Clin Pharmacol 2019;8:469-72. 